\title{
A method for electronically monitoring the ambulatory activity of honeybees under dark conditions
}

\author{
R. S. PICKARD and D. HEPWORTH \\ Department of Zoology, University College, Cardiff, CF1 $1 X L$, United Kingdom
}

\begin{abstract}
An electronic apparatus using infrared beams for monitoring the movements of individual bees under dark conditions is described. The searching behavior of workers in an arena was monitored over 2-h periods. Mean ambulatory velocity for one bee over a distance of $100 \mathrm{~mm}$ was $45.6 \pm 1.51 \mathrm{~mm} / \mathrm{sec}(\mathrm{n}=45)$. Thigmokinesis and temporal activity patterns are illustrated.
\end{abstract}

The accurate monitoring of movement under low levels of visible light, or in its complete absence, remains a considerable problem. The apparatus described here utilizes infrared illumination with $\lambda 940 \mathrm{~nm}$ for the monitoring of movement.

The visual spectral sensitivity of honeybees (Apis mellifera $L$.) is generally considered to be within the $\lambda$ range of 300 to $700 \mathrm{~nm}$ (Bertholf, 1931; Daumer, 1956; Kühn, 1927; Menzel, Erber, \& Masuhr, 1974; Thomas \& Autrum, 1965). Gribakin (1969) recorded a sensitivity peak at $\lambda 530 \mathrm{~nm}$ in dark-adapted bees. Studies of the infrared sensitivity of insect species have been investigated, and the absence (Goldsmith, 1965) and presence (Evans, 1964) of specific infrared/red receptors have been reported. There is no evidence to suggest that honeybees have specific infrared receptors or are visually sensitive to the $\lambda$ range of 800 to $32,000 \mathrm{~nm}$ (Barker, 1972). Bees are sensitive to the thermal properties associated with high amplitude infrared radiation (Butler \& Finney, 1942).

The honeybee has been reported to show both tropotactic and telo-tactic ambulatory behavior in the presence of a visible light source (Fraenkel \& Gunn, 1940; Minnich, 1919). The factors determining the orientation, locomotion, and searching behavior of bees under dark conditions are not known at present.

\section{MATERIALS AND METHOD}

A tall, light-tight wooden box $(400 \times 100 \times 100 \mathrm{~mm})$ was coated internally with nonreflective black paint. One side of the box could be opened for access to the interior. A removable glass arena $(10 \times 100 \times 100 \mathrm{~mm})$ was positioned horizontally at the center of the box with an array of 25 infrared emitters [Texas Instruments Ltd. (TIL 31)] mounted above and another 25 infrared sensors (TIL 81) mounted below it (Figure 1). The

Some of the equipment used in this pilot study was provided by the Science Research Council. D. H. was financially supported by a University of Wales scholarship. Additional support was provided by the British Beekeepers' Association, Welsh Beekeepers' Association, and the Central Association of Beekeepers. Helpful advice was given by Mr. G. Jones on electronics, Mr. A. Jones on photography, and Mr. C. Welsby and Mr. G. Robinson on construction. emitters and sensors in a given array were positioned $20 \mathrm{~mm}$ apart horizontally. In this configuration, the entire volume of the arena was irradiated with infrared light, the level of which was independently recorded in each of the 25 sectors monitored by the TIL 81 sensors. These were adjusted such that a bee introduced into the arena could not avoid interrupting a light path to a given sensor. The sensors were powered by a $3-\mathrm{V} \mathrm{dc}$ supply with a diode in circuit to accentuate the detection of falling infrared light levels (Figure 2). An exposed sensor had a low resistance to current flow and generated a positive charge at the diode's cathode, preventing it from passing current. As a bee obstructed the light falling on the sensor, sensor resistance increased, the diode was relieved of the blocking charge and conducted current. Voltage changes in the diode's circuit were proportional to the masking of the sensor by the bee.

To study a bee's searching pattern against time, the sensor outputs are individually displayed on a Tektronix $5103 \mathrm{~N}$ storage oscilloscope and photographed with a Polaroid CR-9 camera. To study overall locomotory activity irrespective of search pattern, the outputs of the sensors are integrated, filtered, and converted to square wave pulses through a Neurolog voltage window discriminator (Digitimer Ltd.). The pulses are then electronically counted and the count mechanically printed at 5-min intervals. The photocells are adjusted such that a bee has to obstruct most of the light falling on a sensor to register a single counting pulse. This excludes the possiblity of counts being generated by antenna, wing, or leg movements. The outputs are calibrated and equilibrated by obstructing each sensor, in turn, with cardboard squares of known areas.

In control trials, the bees do not appear able to detect the 940-nm infrared wavelength used in this apparatus and are unable to use the TIL 31 emitter as an exit indicator in a lighttight container. Any heat produced by the emitters is uniformly dispersed over the area of the arena and continuously monitored. The temperature in the arena ranges from 17 to $28.5^{\circ} \mathrm{C}$, with a mean of $20.5^{\circ} \mathrm{C} \pm .33 \mathrm{SE}(\mathrm{n}=52)$.

The apparatus was used to record individual ambulatory activity in 52 worker honeybees, each for a 2 -h period, providing $104 \mathrm{~h}$ of continuous recording. For each trial, groups of four bees were taken from a hive entrace and fed on $30 \%$ sucrose solution for $1 \mathrm{~h}$ in a plastic container, $170 \times 115 \times 40 \mathrm{~mm}$, under prevailing daylight conditions. One of the four bees was then introduced into the dark arena; the three hive companions were isolated from their colony to avoid accidental reselection. To allow for periodicity in the bees' performance (Koltermann, 1974), successive trials followed a rota of starting times: $09: 15$; $11: 15 ; 13: 15 ; 15: 15$ (hours:minutes).

\section{RESULTS}

The apparatus monitored ambulatory activity both 
a.

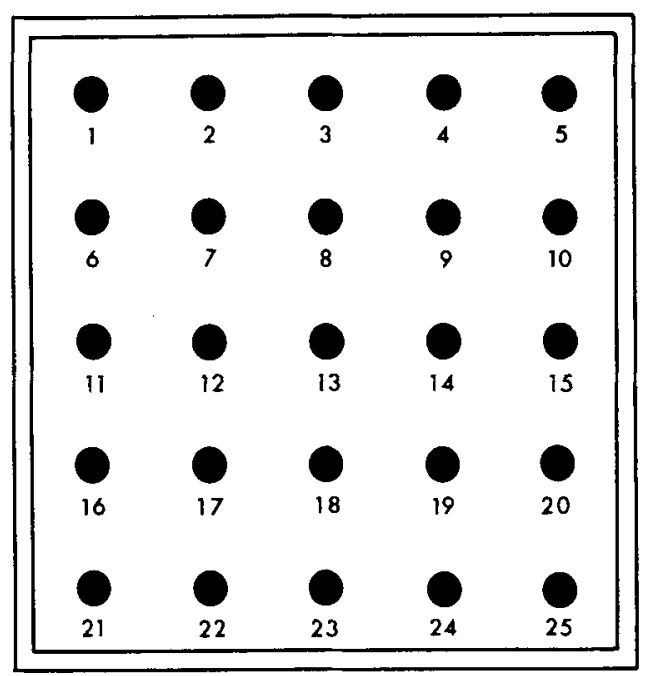

b.

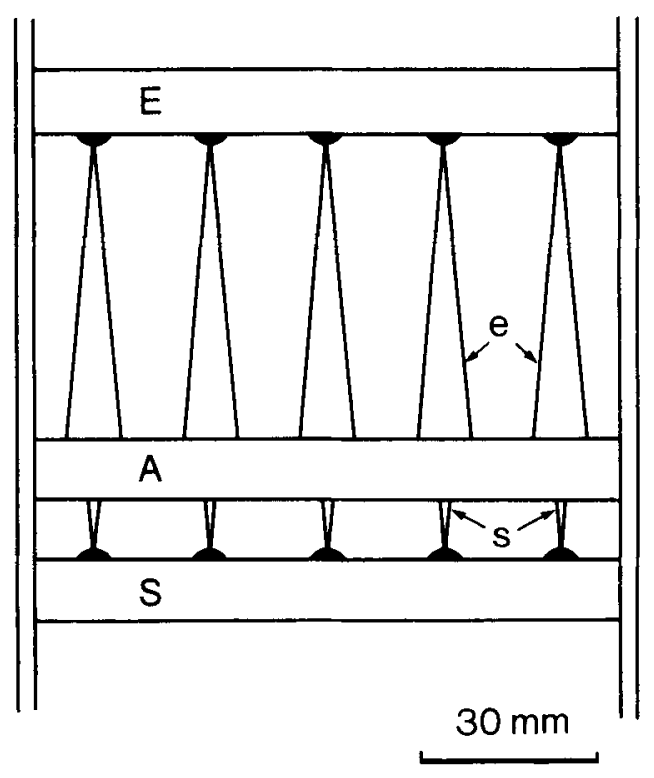

Figure 1. Activity monitoring box. (a) Plane view of photocell array: 1-25, photocells. (b) Vertical median section through box. A, arena; E, emitter array; e, emitter beams; $S$, sensor array; $s$, sensor acceptance angles.

qualitatively and quantitatively. The sensors detected occlusions of $.2 \mathrm{~mm}^{2}$ and resolved discontinuous movements with an interval of $1 \mathrm{msec}$. The results showed no seasonal variation but suggested circadian periodicity, which is being investigated further. The searching patterns of individual bees seeking an exit from the arena were analyzed. Extremely rapid walking movements were monitored (see Figure 3a). During the first $20 \mathrm{~min}$ of an experiment, the mean ambulatory velocity for one bee over a distance of $100 \mathrm{~mm}$ was $45.6 \pm 1.51$
SE $(\mathrm{n}=45) \mathrm{mm} / \mathrm{sec}$ and the maximum ambulatory velocity was $59.88 \mathrm{~mm} / \mathrm{sec}$. The bees appeared to orient with respect to the sides of the arena, with periodic excursions into the center. This thigmokinesis resulted in bees tending to follow a circular route around the arena periphery (Figure $3 b$ ). The locomotory pattern was frequently interrupted by gross retrospective searching movements, often eilicited when a bee entered a 90-deg comer (Figure 3c).

To quantify the activity, occlusions of the sensors greater than $4 \mathrm{~mm}^{2}$ were allowed to trigger uniform counting pulses irrespective of the analogue waveform produced by occlusion (Figure 4a). The discriminator detected fine retrospective oscillations by bees hesitating at points in the arena (Figure 4b), together with successive rapid movements (Figure 4c). Although the former characteristic prevented the conversion of standard photocell counts into absolute distance walked, it demonstrated the possibiltiy of using this apparatus

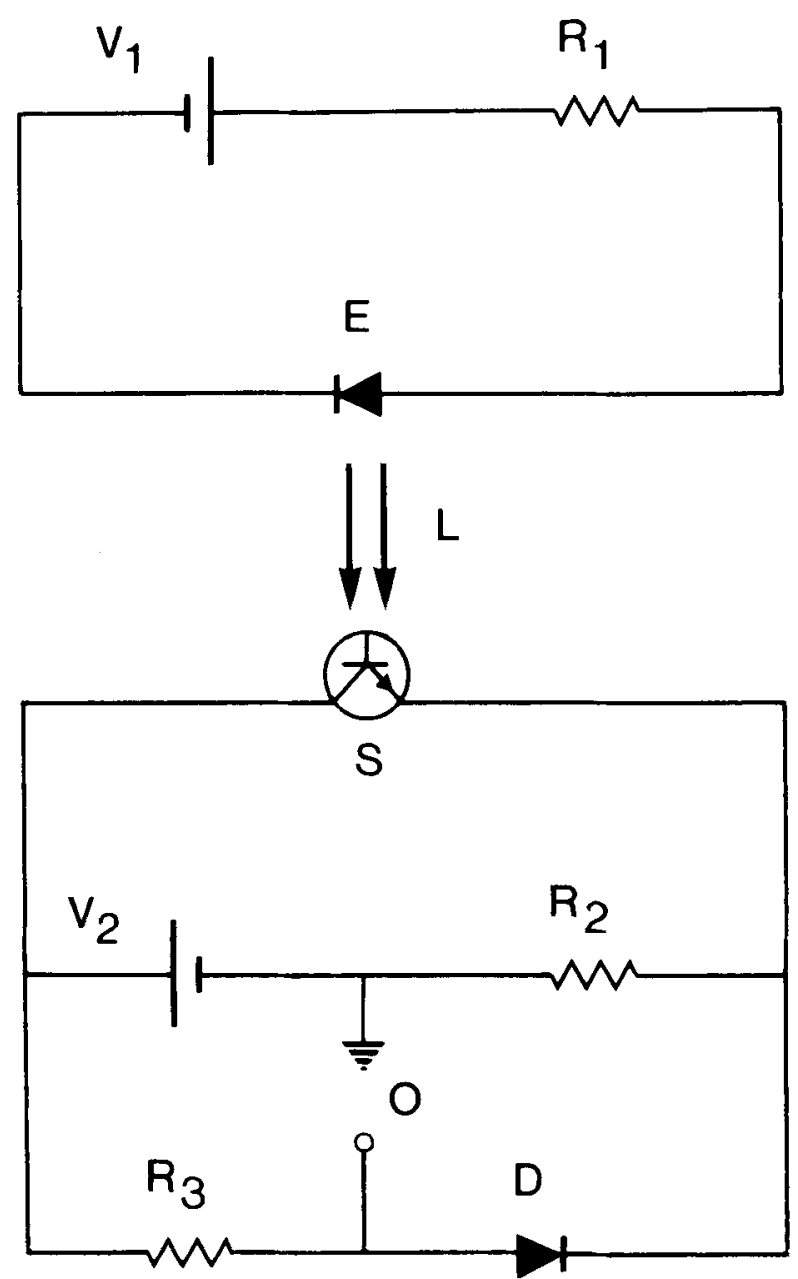

Figure 2. Photocell circuit diagram. D, diode 1N4148; $E$, emitter; $L$, infrared light; 0 , output; $R_{1}, 220 \mathrm{ohm} ; R_{2}$, $1 \mathrm{kohm} ; R_{3}, 10 \mathrm{kohm}$; sensor; $V_{1}, 7 \mathrm{~V} ; \mathrm{V}_{2}, 3 \mathrm{~V}$. 


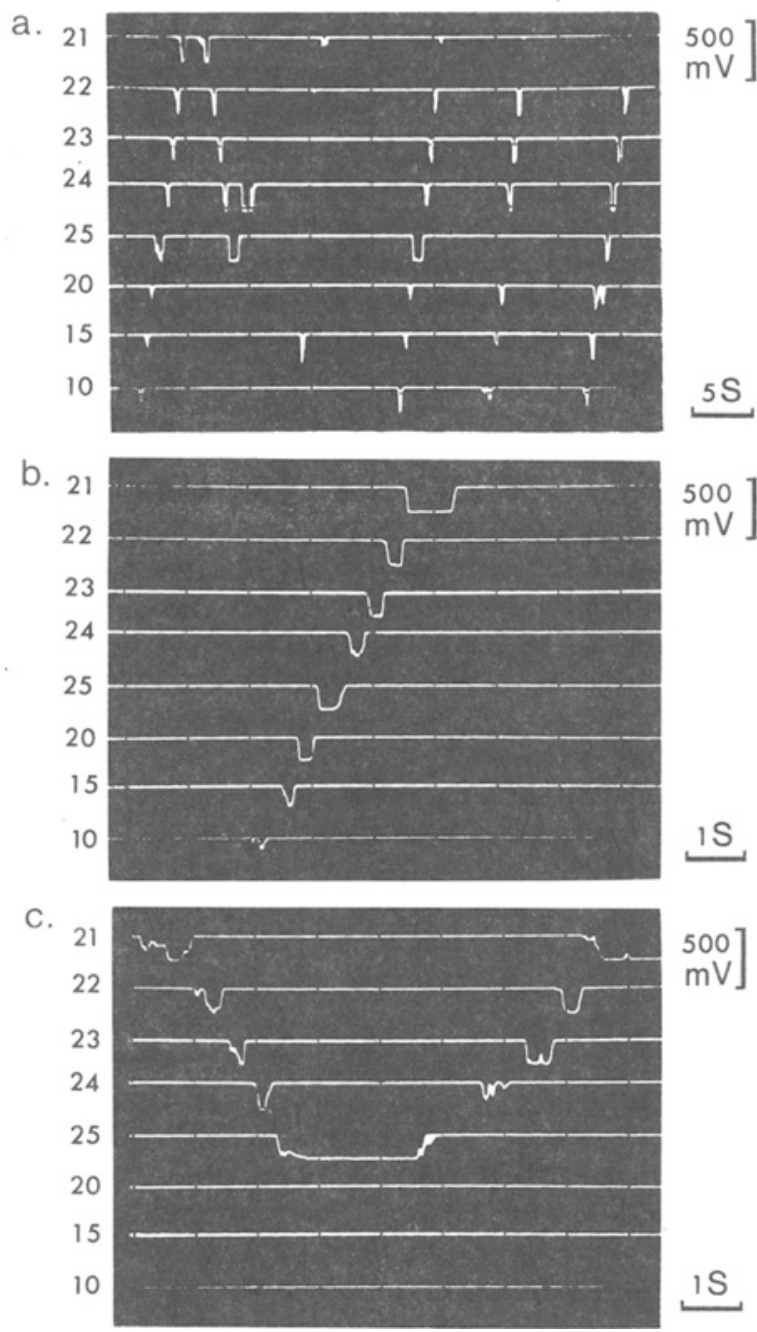

Figure 3. Searching patterns of individual bees. Simultaneous oscilloscope displays of sensor outputs. Downward movement of a trace indicates that a bee is occluding the light to a given sensor. (a) General activity pattern, (b) circling the arena, (c) gross retrospective movement from a corner. Sensor positions in array as numbered.

to monitor a bee's movements while investigating a localized target, such as a scent source. If all sensor channels were discriminated separately, photocell count could be expressed in terms of absolute distance moved.

Six types of $2 \cdot h$ activity patterns were clearly distinguishable. These are illustrated in Figure 5. Whether these are the result of simple individuality in the experimental bees or betray the presence of a heterogeneous population with discrete subgroups determined by age, occupation, or physiological state remains obscure. If mean activity figures are calculated for each 5-min period, the population as a whole displays a remarkably consistent activity profile over a 2 -h period (Figure 6). Activity increased during the first $20 \mathrm{~min}$ after introduction to the arena and then decreased almost linearly for a further $100 \mathrm{~min}$. During that period, the fall in activity was about $35 \%$.

\section{DISCUSSION}

The apparatus proved successful in monitoring ambulatory movement under dark conditions. It avoided any need for mechanical interaction between subject and sensor, as required by the monitoring devices of Spangler (1972) and Kramer (1976). The response delay of the TIL 81 sensors of less than 10 microsec allowed an accurate definition of rapid movement. The infrared beams did not appear to affect the bees in any obvious way and their use as behavior event recorders seems assured (Grossman \& Beller, 1971). The photocells are extremely sensitive. They can be used to cover a large area and are reliable over months of use. They are also

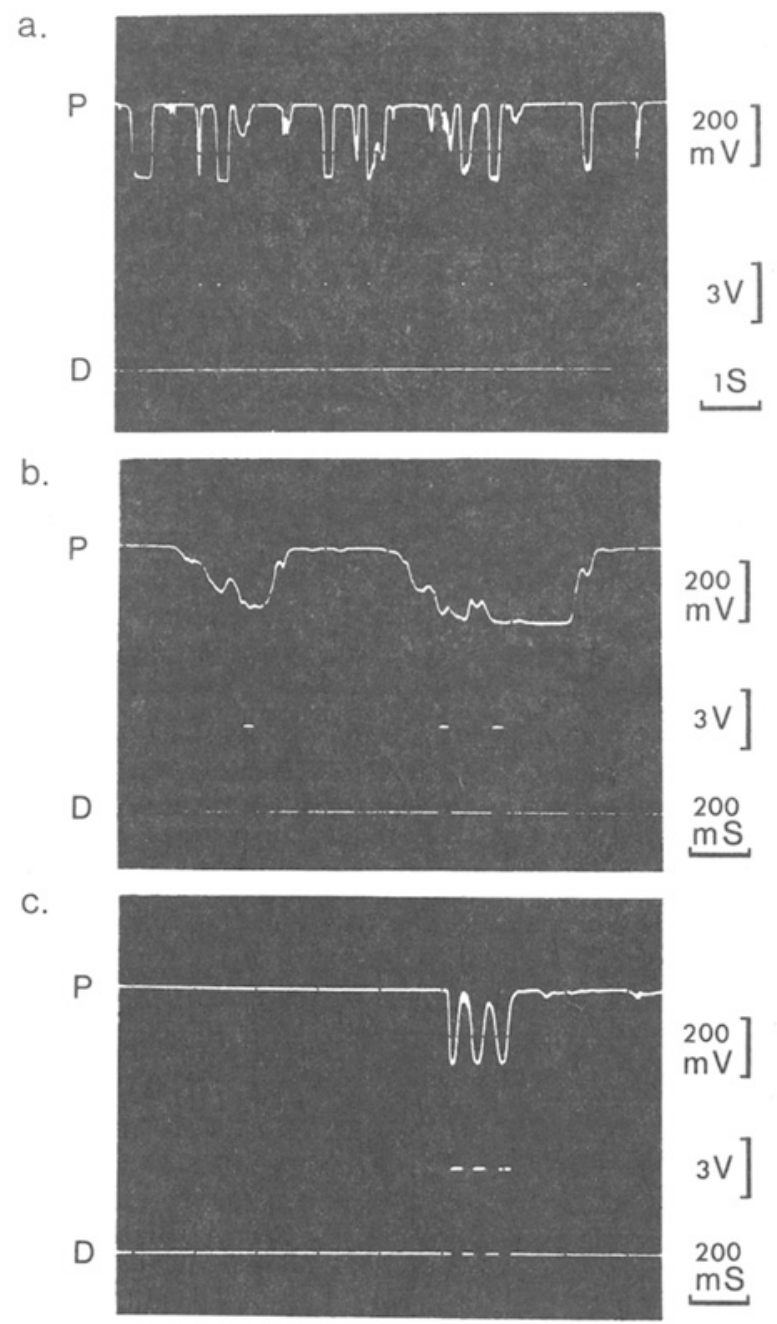

Figure 4. Simultaneous oscilloscope displays of 25 sensor outputs integrated (P) and discriminator output (D). Discrimination of (a) major sensor occlusions, (b) fine retrospective movements, (c) rapid gross movements. 

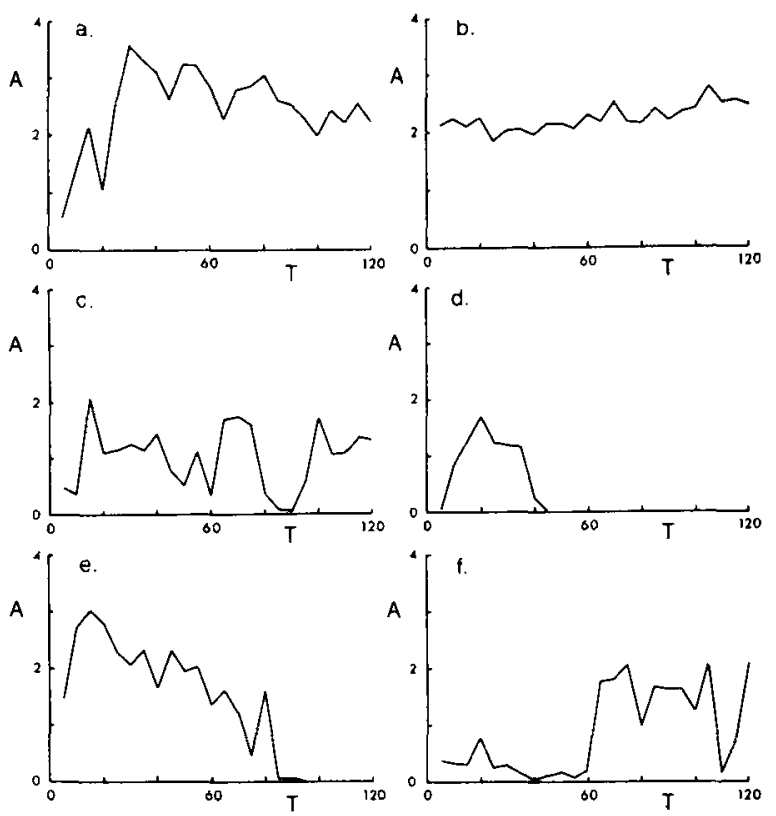

Figure 5. Six temporal patterns of ambulatory activity produced by individual bees. $A$, activity in standard photocell counts; $T$, time in minutes.

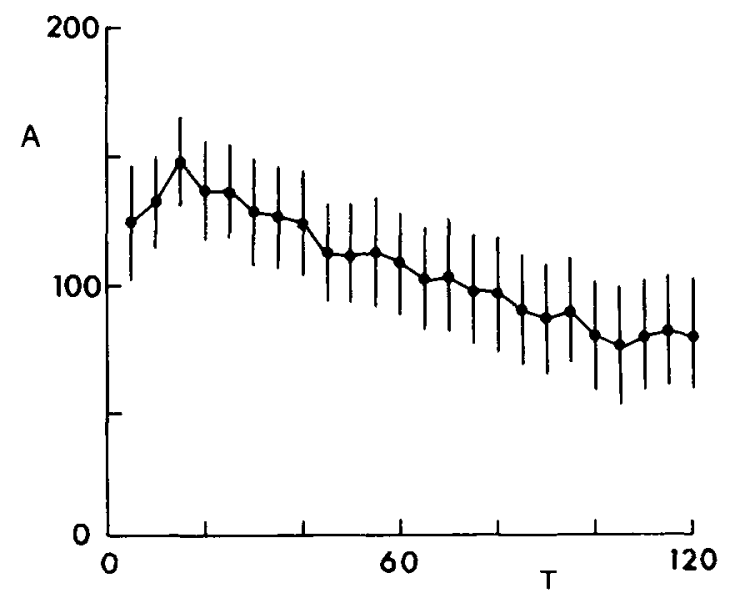

Figure 6. Mean ambulatory activity of experimental population. $A$, activity in standard photocell counts; $T$, time in minutes. Plotted to indicate $95 \%$ confidence limits $(n=52)$.

inexpensive to use compared with cine photography and avoid focusing problems; the automated control facilitates objective analysis of data. In addition, paired emitters and sensors can be placed within hives or around flowers, wherever movement has to be moni- .rred. MOSFET integrated circuits can be used to multiplex outputs from hundreds of sensors on to a small number of wires where bulky cables are inappropriate. FM telemeters can be added to TIL 81 packages for remote recording of data. Although this account has concentrated on monitoring under dark conditions, the apparatus functions equally well under uniform illumination with visible light.

\section{REFERENCES}

BARKER, R. J. Is there any evidence that honeybees are attracted by infrared? Bee World, 1972, 53, 66-68.

Be RTHOLF, L. M. Reactions of the honeybee to light. Journal of Agricultural Research, 1931, 42, 379-419.

Butle R, C. G., \& Finney, D. J. The influence of various physical and biological factors of the environment on honeybee activity: An examination of the relationship between activity and solar radiation. Journal of Experimental Biology, 1942, 18, 206-212.

Daumer, K. Reizmetrische untersuchung des farbensehens der biene. Zeitschrift für Vergleichende Physiologie, 1956, 38, 413-478.

Evans, W. G. The orientation of Melanophila acuminata DeGeer (Coleoptera, Buprestidae) to fires. Proceedings of the XII International Congress on Entomology, 1964, 286.

Fraenkel, G. S., \& GunN,, D. L. The orientation of animals. Oxford: Clarendon Press, 1940.

Goldsmith, T. H. Do flies have a red receptor? Journal of General Physiology, 1965, 49, 265-287.

GRIBAKIN, F. G. Cellular basis of colour vision in the honeybee. Nature (London), 1969, 223, 639-641.

Grossmann, K. E., \& Beller, E. J. Das erlernen unbelohnter farbisgnale durch honigbienen. Zeitschrift fitr Tierpsychologie, $1971,29,449.466$.

Koltermann, R. Periodicity in the activity and learning performance of the honeybee. In L. B. Browne (Ed.), Experimental analysis of insect behaviour. Berlin: Springer-Verlag, 1974. Pp. 218-227.

Kramer, E. The orientation of walking honeybees in odour fields with small concentration gradients. Physiological Entomology, $1976,1,27-37$.

KüHN, A. Über den farbensinn der bienen. Zeitschrift für Vergleichende Physiologie, 1927, 5, 762-800.

Menzer, R., Erber, J., \& Masuhr, T. Learning and memory in the honeybee. In L. B. Browne (Ed.), Experimental analysis of insect behoviour. Berlin: Springer-Verlag, 1974. Pp. 195-217.

Minnich, D. E. The photic reactions of the honeybee, Apis mellifera L. Journal of Experimental Zoology, 1919, 29, 343-425.

SPANGLER, H. G. Daily activity rhythms of individual worker and drone honeybees. Annals of the Entomology Society of America, 1972, 65, 1073-1076.

Thomas, I., \& Autrum, H. Die empfindlichkeit der dunkel und helladaptierten biene fur spektrale farben: zum Purkinje phanomen der insekten. Zeitschrift für Vergleichende Physiologie, 1965, 51, 204-218.

(Received for publication May 21, 1979; accepted June 12, 1979.) 